\title{
The secE gene encodes an integral membrane protein required for protein export in Escherichia coli
}

\author{
Peter J. Schatz, Paul D. Riggs, ${ }^{1}$ Annick Jacq, Michael J. Fath, and Jon Beckwith \\ Department of Microbiology and Molecular Genetics, Harvard Medical School, Boston, Massachusetts 02115 USA
}

\begin{abstract}
Genetic screening and selection procedures employing a $\sec A-l a c Z$ fusion strain repeatedly have yielded mutations in four genes affecting the protein export pathway of Escherichia coli. These genes are secA, secD, prlA/secY, and secE. We discuss the significance of the failure to find new $\sec$ genes after extensive use of this approach. One of the genes, secE, has been characterized in some detail. From the DNA sequence of the gene and analysis of alkaline phosphatase fusions to the SecE protein, we propose that it is a 13,600-dalton integral cytoplasmic membrane protein. The data presented here and in the accompanying paper strongly suggest that secE has an important role in $E$. coli protein export.
\end{abstract}

[Key Words: E. coli; secretion; TnphoA; membrane protein; secE]

Received March 7, 1989; revised version accepted April 25, 1989.

In Escherichia coli proteins destined for the cell envelope require a cellular machinery for the export process. Genetic studies have revealed the existence of five genes, $\sec A, \sec B$, $\sec D$, $\sec E$, and $p r l A / \sec Y$, whose products are required for protein translocation across the cytoplasmic membrane (Emr et al. 1981; Oliver and Beckwith 1981; Kumamoto and Beckwith 1983; Shiba et al. 1984; Bankaitis and Bassford 1985; Gardel et al. 1987; Riggs et al. 1988). So far, the products of three of these genes, $\sec A, \sec B$, and $\sec Y$, have been shown to play a role in the functioning of bacterial in vitro translocation systems (Bacallo et al. 1986; Fandl and Tai 1987; Cabelli et al. 1988; Collier et al. 1988; Kumamoto et al. 1989).

Recently we described a new genetic screening procedure for obtaining mutations in sec genes (Riggs et al. 1988). This procedure is based on the finding that the synthesis of the SecA protein is derepressed when the export pathway is blocked (Oliver and Beckwith 1982). For instance, mutations in certain sec genes, which cause pleiotropic defects in protein export, result in an increased expression of the $\sec A$ gene. We found that with a $\sec A-l a c Z$ gene fusion, $\beta$-galactosidase also was derepressed in strains carrying sec mutations. Thus, by using either selection or screening procedures for increased $l a c Z$ expression with the $\sec A-l a c Z$ fusion in an otherwise $\mathrm{sec}^{+}$background, we obtained a collection of new sec mutants. (The strain also carries a wild-type $\sec A$ gene on a $\lambda$-transducing phage, as this gene is essential for growth.) This collection included mutations in the known $\sec$ genes, $\sec A$, $\sec D$, and $p r l A / \sec Y$. Mu-

'Present address: New England Biolabs, Beverly, Massachusetts 01915 USA. tations in $\sec B$, which affect only a subset of exported proteins (Kumamoto and Beckwith 1985), did not appear in this collection. However, a mutation in a new gene $\sec E$, was detected in this way. A secEcs mutation was mapped to minute 90 on the E. coli chromosomal map.

In this paper we report the results of a more extensive use of this new procedure for obtaining sec mutants. Despite the accumulation of a large collection of mutants, no new $\sec$ genes were identified. In addition, we have mapped the precise position of the $\sec E$ gene and obtained new mutations in it. $\sec E$ corresponds to an open reading frame $(O R F)$ identified by Downing and coworkers (W. Downing, S. Sullivan, M. Gottesman, and P. Dennis, in prep.). On the basis of the amino acid sequence corresponding to the ORF and on the properties of alkaline phosphatase (AP) fusions to SecE, we propose that the protein is located in the E. coli cytoplasmic membrane.

\section{Results \\ A search for new sec genes}

We have continued our use of the $\sec A-l a c Z$ fusion strain to select and screen for mutants in hitherto undetected $\sec$ genes. The $\sec A-l a c Z$ joint creates a translational fusion between $\sec A$ and $l a c Z$ plus a transcriptional fusion to the downstream $\operatorname{lacY}$ and $\operatorname{lac} A$ genes (Riggs et al. 1988). Previously, we described three procedures for obtaining mutants that were enhanced for the expression of the fusion (Riggs et al. 1988). Here, we 
continue the use of two of these: (1) the selection for growth on raffinose as a carbon source, which selects for increased expression of the lacY gene; and (2) screening for increased lac $Z$ expression on lactose indicator plates containing the $\beta$-galactosidase inhibitor, phenylethyl- $\beta$ $D$-thiogalactoside (tPEG). The strain used in these procedures was PR478, which differs from the strain used previously only in that it does not carry a Tn5 inserted in the leu operon (Table 1).

In the first set of selections, we sought only those mutants in which a conditional lethal phenotype was associated with the increased expression of the $\sec A-l a c Z$ fusion. From a selection on raffinose minimal medium at either $37^{\circ} \mathrm{C}$ or $30^{\circ} \mathrm{C}$, we obtained 27 mutants with increased lacY expression. These were screened for coldsensitive or temperature-sensitive growth on rich medium. One of the two cold-sensitive mutants (both failed to grow at $23^{\circ} \mathrm{C}$ ) found was due to a mutation linked by Pl transduction to the $\sec Y$ gene, and the other, to a mutation linked to the $\sec D$ gene. No temperature-sensitive mutants (failed to grow at $42^{\circ} \mathrm{C}$ ) were found.

Using the indicator plate screen, we examined $99 \mathrm{mu}$ tants obtained from ethylmethane sulfonate (EMS) mutagenesis at $30^{\circ} \mathrm{C}$ and 200 obtained at $37^{\circ} \mathrm{C}$. Of the former, three cold-sensitive mutants were due to mutations linked to $\sec D$ and two temperature-sensitive mutants were due to mutations linked to $\sec A$. From the latter, 17 cold-sensitive mutants were due to mutations linked to $\sec D, 4$ to mutations linked to $\sec A$, and 3 to mutations linked to secY. One cold-sensitive mutant was caused by a double mutation; one of the mutations, which was in the $\sec E$ gene, as shown by complementation, did not confer cold sensitivity by itself. The cold- sensitive mutation in this strain and in a number of others did not map to known sec genes. However, in all cases, these mutations had only slight effects on the expression of the $\sec A-l a c Z$ fusion and no measurable effect on protein export, as determined by the accumulation of the precursor to maltose-binding protein (MBP).

Finally, we repeated the mutant hunt, using EMS mutagenesis and the screen on indicator plates, but this time screening all mutants by genetic mapping to determine whether they were due to mutations in new sec genes. Of 49 mutants examined, 7 mapped to $\sec A, 10$ to $\sec D$, and 2 to secY. The other mutations were either linked to the $\sec A-l a c Z$ fusion or had only very weak effects $(<50 \%$ increase) on the expression of the fusion.

Thus, the results of all these selections and screenings for sec mutants were 49 mutants, all of which were probably due to mutations in $s e c$ genes known already. In our previous screenings for mutants (Riggs et al. 1988), we obtained 11 mutants that mapped to the known sec genes.

\section{Characterization of the secE gene: secEcsE501 is recessive}

A previous study had shown the secEcsE501 mutation to be located at $\sim 90 \mathrm{~min}$ on the $E$. coli chromosome, with Pl cotransductional linkage of $50 \%$ to $\arg E, 10 \%$ to met $A$, and $40 \%$ to met $B$ (Riggs et al. 1988). To test whether the secEcsE501 mutation was recessive, we moved the $F^{\prime} K L F 10$ in strain PR535, carrying an $\operatorname{argE}:: \operatorname{Tn} 10$ allele, into a secEcsE501 secA-lacZf181 recA1 zij :: Tn5 strain (PR560) by conjugation. The $\mathrm{F}^{\prime} \mathrm{KLF} 10$ carries the region of the E. coli chromosome

Table 1. E. coli strains

\begin{tabular}{|c|c|c|}
\hline Strain & Genotype & Source \\
\hline $\mathrm{MC} 4100$ & $\begin{array}{l}\mathrm{F}^{-} \text {lacsU169 araD139 rpsL150 thi- } \\
\text { flbB5301 deoC7 ptsF25 relA1 }\end{array}$ & laboratory collection \\
\hline $\mathrm{CC} 118$ & $\begin{array}{l}\mathrm{F}^{-} \text {araD139 } \Delta 7697(\mathrm{ara}-\mathrm{leu}) \\
\Delta X 74(\mathrm{lac}) \text { phoA } 220 \mathrm{galE} \text { galK } \\
\text { thi- }{ }^{-} \text {rpsE rpoB argEam recA1 }\end{array}$ & laboratory collection \\
\hline MUT1 & $\mathrm{F}^{-}$mutD5 metE lacZ trpA & laboratory collection \\
\hline PR478 & MC4100 secA-lacZ-f181 ( $\lambda$ PR9) & this study \\
\hline PR500 & $\begin{array}{l}\text { MC4100 secA-lacZ-f181 (入 PR9) } \\
\quad \text { secEcsE501 zij :: Tn5 }\end{array}$ & this study \\
\hline PR521 & $\begin{array}{l}\text { MC4100 secA-lacZ-f181 ( } \lambda \text { PR9) } \\
\quad \text { secEcsE501 } \operatorname{argE}:: \operatorname{Tn} 10 \text { zij :: Tn5 }\end{array}$ & this study \\
\hline PR535 & 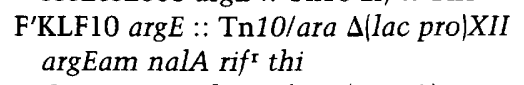 & this study \\
\hline PR560 & $\begin{array}{c}\text { MC4100 secA-lacZ-f181 ( } \lambda \text { PR9) } \\
\text { secEcsE501 recA1 zij :: Tn5 }\end{array}$ & this study \\
\hline PS8 & MC4100 secEcsE501 recA :: cat & this study \\
\hline PS137 & MC4100 secEcs 11 argE $:: \operatorname{Tn} 10$ & this study \\
\hline PS138 & MC4100 secEcs12 argE :: Tn10 & this study \\
\hline PS139 & MC4100 secEcs13 argE :: $\operatorname{Tn} 10$ & this study \\
\hline PS140 & MC4100 secEcs14 argE :: Tn10 & this study \\
\hline PS141 & MC4100 $\arg E:: \operatorname{Tn} 10$ & this study \\
\hline PS169 & MC4100 recA :: cat & this study \\
\hline MJC98 & $\begin{array}{l}\mathrm{F}^{-} \Delta \mathrm{X} 74(\text { lac) gale galK rplL } \\
\quad \Delta \text { phoA-PvuII pcnB-80 zadl :: Tn10 }\end{array}$ & Mike Carson \\
\hline
\end{tabular}


from minute 87 to 91 . Of the $\mathrm{Kan}^{\mathrm{r}} \mathrm{Tet}^{\mathrm{r}}$ exconjugants, $100 \%$ grew normally at $23^{\circ} \mathrm{C}$ (complementation of the cold-sensitive defect) and showed normal levels of expression of the $\sec A-l a c Z$ fusion (complementation for overexpression of $\sec A$ ). This indicates that the $\mathrm{F}^{\prime}$ carries the $\operatorname{secE}^{+}$gene, which complements the chromosomal secEcsE501 mutation. We confirmed the presence of the secEcsE501 mutation by growing phage P1 on this strain, using the lysate to transduce PR478 to $\mathrm{Kan}^{\mathrm{x}}$ and demonstrating cotransduction of the secEcs mutation.

\section{Further mapping of the secE gene}

A portion of the $E$. coli chromosome at $\sim 89 \mathrm{~min}$ is carried on the $\lambda$ specialized transducing phage, $\lambda \mathrm{d} r i f^{\mathrm{d}} 18$ (Kirshbaum and Konrad 1973; An and Friesen 1980). This $\lambda$ phage carries the rpoB and rpoC genes, a cluster of genes involved in translation, and the $\operatorname{rrn} B$ rRNA operon. To test whether the $\sec E^{+}$gene was present on $\lambda$ drif 18 , we constructed a double lysogen by infecting a secEcsE501 secA-lac $Z$ strain (PR500) with this phage and a wild-type $\lambda$ helper phage at $37^{\circ} \mathrm{C}$. Of the Rifr lysogens, $100 \%$ were complemented for both the cold-sensitive defect and overexpression of the $\sec A-l a c Z$ fusion. This indicates that the $\sec E$ gene is present on $\lambda$ drif 18 .

We attempted to localize the $\sec E$ gene further using portions of the chromosomal insert on $\lambda$ drif ${ }^{d} 18$ that had been subcloned on high-copy-number plasmids (Fiil et al. 1979; An and Friesen 1980). A secEcsE501 secA-lacZ strain (PR500) was transformed with pNF1344, pGA61, and pGA100 (see Fig. 1) and scored for complementaion of the cold-sensitive defect and overexpression of the $\sec A-1 a c Z$ fusion. Only plasmid pGA61 showed any complementation: full complementaion of the $\sec A$ -
lacZ overexpression and partial complementation for growth at $23^{\circ} \mathrm{C}$. Overexpression of some ribosomal proteins on high copy plasmids can lead to a growth defect, presumably due to a defect in translation (Fiil et al. 1979|. Because translational defects can suppress sec defects (Lee and Beckwith 1986), the partial complementation of the secEcsE501 phenotype by pGA61 is not conclusive but suggests that the $\sec E$ gene lies between $r p l K$ and $\operatorname{tuf} B$. We used a $\lambda$ phage that carries this region, $\lambda$ YU101, to lysogenize a secEcsE501 secA-lacZ strain (PR500), using wild-type $\lambda$ as a helper phage. The $\lambda$ YU101 prophage complemented the secEcsE501 cold sensitivity and $\sec A-l a c Z$ overexpression phenotypes completely. We confirmed the presence of the secEcs allele in this lysogen by P1 transduction as described in the previous section. This confirms that the secE gene lies between $r p l K$ and $t u f B$. The high-copy plasmid pBRU (W. Downing, S. Sullivan, M. Gottesman, and P. Dennis, in prep.), which carries the same region as $\lambda$ YU101, also complemented the secEcsE501 phenotypes.

\section{secE encodes a small membrane protein}

The $\lambda$ YU101 phage and the pBRU plasmid have a 2.2-kb insert that spans a region from the middle of the tuf $B$ gene to the $r p l K$ gene (Fig. 1). The sequence of the region between $\operatorname{tufB}$ and $\operatorname{rplK}$ (W. Downing, S. Sullivan, $M$. Gottesman, and P. Dennis, in prep.) reveals two large ORFs that encode polypeptides of predicted molecular weights 13,600 and 20,500. The larger of these two ORFs encodes the ' $U^{\prime}$ protein (Yamamoto and Nomura 1979). These two coding sequences appear to be part of a single operon, with the coding sequence for the $20.5-\mathrm{kD}$ ' $\mathrm{U}$ ' protein downstream. The ' $U$ ' protein has been identified by Downing et al. (W. Downing, S. Sullivan, M. Got-

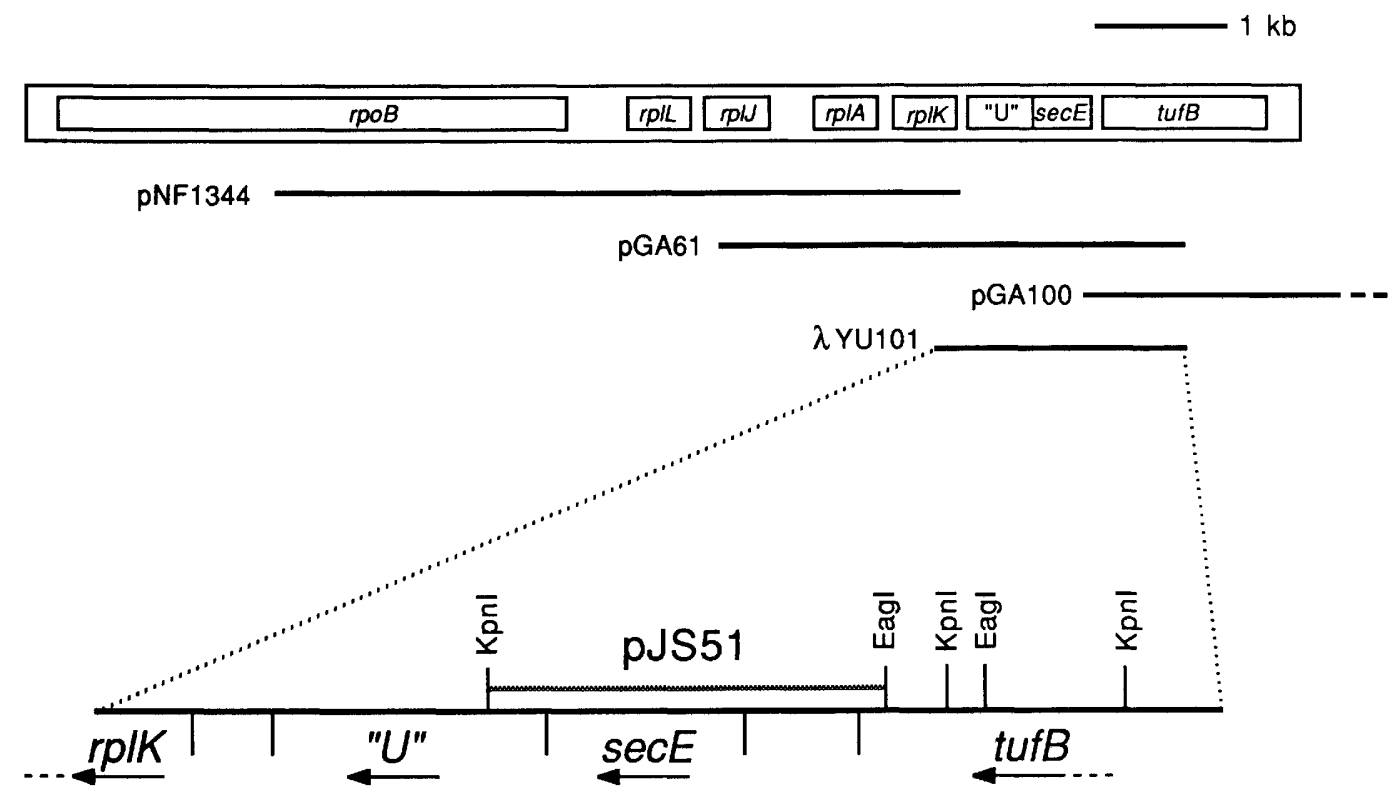

Figure 1. Physical map of the $\sec E$ region. (Top) The region of the $E$. coli chromosome near the $\sec E$ gene, including the regions contained in the plasmids pNF1344, pGA61, and pGA100 and in the phage $\lambda$ YU101. (Bottom) An expanded view of the region carried by $\lambda$ YU101 (and plasmid pBRU) showing the fragment contained by the $\sec E$ subclone pIS51. 
tesman, and P. Dennis, in prep.) as a factor involved in transcription. To determine whether the upstream gene was $\sec E$, we subcloned a $0.8-\mathrm{kb}$ EagI-KpnI fragment containing all of the first ORF and less than one-third of the second. This subclone (pJS51) complemented all of the phenotypes of the secEcsE501 allele. Because the first ORF was the only one encoding a substantial polypeptide on the fragment, we concluded tentatively that the $13.6-\mathrm{kD}$ protein was the product of the $s e c E$ gene.

The deduced sequence of the SecE protein is shown in Figure 2. The protein contains three regions of 18 or 19 uncharged amino acids with a high proportion of hydrophobic residues. Such regions commonly are identified as membrane-spanning stretches of integral membrane proteins (Kyte and Doolittle 1982). Figure 2 shows a proposed model of the topology of the SecE protein in the bacterial cytoplasmic membrane in which the hydrophobic segments, numbered 1-3, each span the membrane once.

\section{Fusions of SecE to $A P$}

We used protein fusions of SecE to AP to test the hypothesis that SecE was a membrane protein and to examine the topology of SecE in the membrane. Fusion of proteins to AP has been used as a probe of protein localization (Manoil and Beckwith 1985). This analysis relies on the observation that AP is active enzymatically only when exported from the cytoplasm (Boyd et al. 1987b).
The transposon TnphoA contains a deleted form of the AP-encoding $p h o A$ gene lacking its normal export information. It can cause the formation of active fusions only when it transposes into a target gene, in the correct orientation and reading frame, in a region that can direct AP export. Thus, fusions to periplasmic proteins or fusions to regions of membrane proteins that are exported from the cytoplasm generally give rise to AP activity (Manoil and Beckwith 1986).

We constructed fusions of SecE to AP by transposition of $\operatorname{Tn} p h o A$ into the $\sec E$ subclone pJS51, as described in Methods. We identified fusions with various levels of AP activity and selected 11 for detailed study based on restriction mapping of the TnphoA insertion sites /data not shown). Sequencing of the insertion sites revealed that eight fusions were in-frame with the $\sec E$-coding region, one was out-of-frame within $\sec E$, and two were in-frame with the downstream ' $U$ ' gene. The SecE-AP fusion joints are shown in Figure 2, along with the AP activity of strain CC118 carrying each of the plasmids. The fusions are numbered according to the amino acid after which each one inserts, for example, f40 is an insertion after the fortieth amino acid of SecE.

The two insertions in the ' $U$ ' gene, named Uf3 and Uf6, were fused after the third and sixth codons of the ' $\mathrm{U}$ ' gene, respectively. Strains carrying these plasmids produced 150 units (Uf3) and 400 units (Uf6) of AP activity.

Analysis of the AP assay data of the fusions within

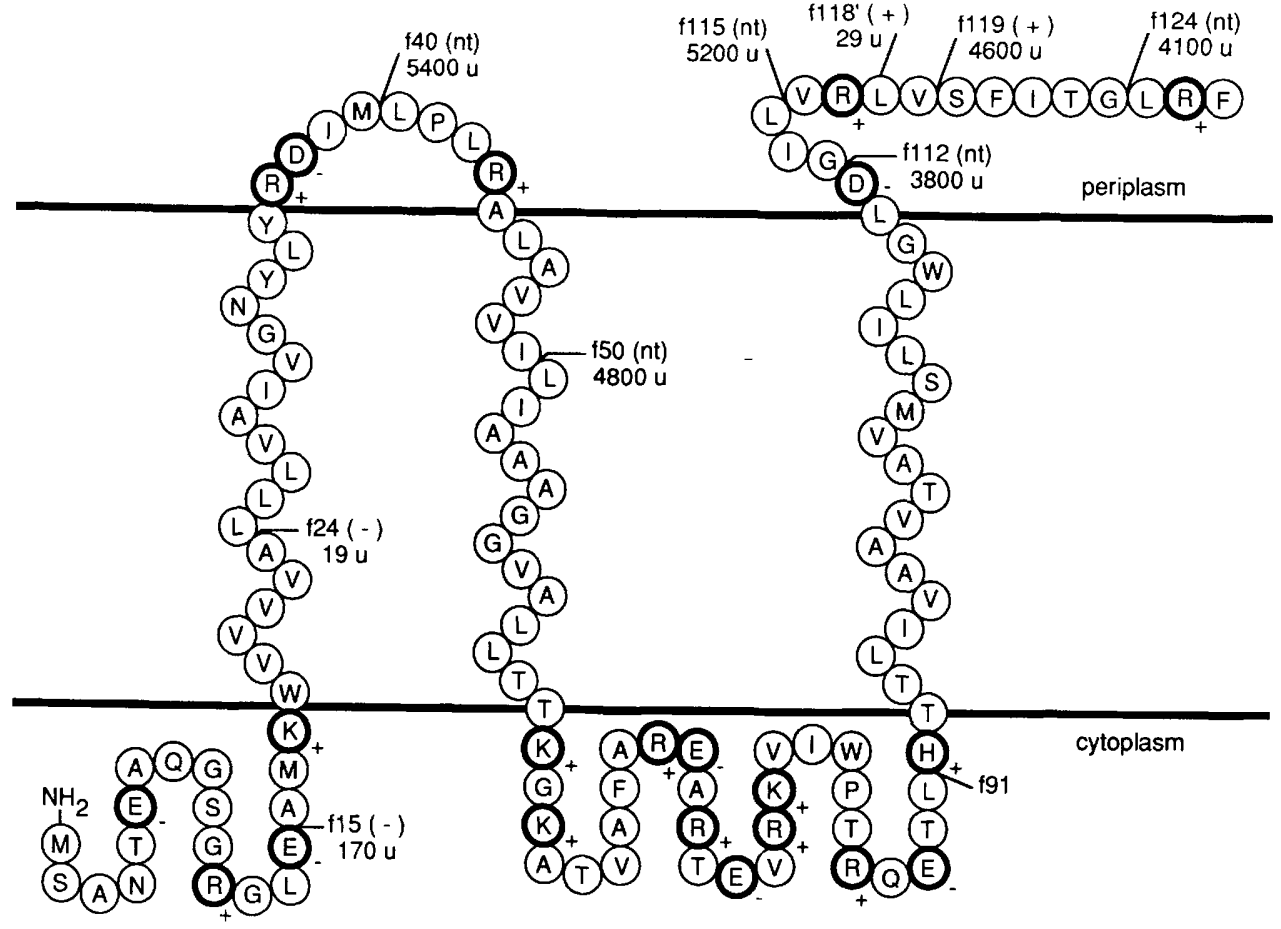

Figure 2. Sequence and proposed topology of SecE in the $E$. coli inner membrane. The SecE amino acid sequence is shown with the amino terminus at the left. The proposed membrane-spanning stretches, positioned between the solid lines, are numbered $1-3$ from left to right. Dark circles represent charged amino acids, with the charges indicated to the lower right. The conformation of the cytoplasmic and periplasmic regions is unknown. The SecE-AP fusion joints are shown, along with the AP activity of strain CC118 carrying each plasmid. Fusion plasmids failed to complement $(-)$ or complemented $(+)$ the secEcsE501 allele. (nt) Fusion plasmids that failed to yield transformants of strain PS8. The properties of fusion $\mathrm{f} 91$ are described in the text. 
$\sec E$ leads to several conclusions. The $\sec E$ ORF is expressed, with the in-frame fusion strains yielding activities from 19 (f24) to 5400 units (f40). The strain with the out-of-frame fusion (f118') expressed only 29 units, although the insertion site was in a region that yielded four extremely active fusions (3800 to 5200 units). The activity of the strains showed a very strong correlation with the position of the fusion joint in the protein. $\mathrm{Fu}$ sions before hydrophobic segment 1 or early in that segment showed relatively low levels of activity. Fusions after segment 1 or early in segment 2 expressed high levels of activity. Fusions after segment 3 produced high levels of activity. Assuming that the SecE protein crosses the membrane three times, these data suggest the topology depicted in Figure 2.

To confirm that these activity measurements reflected the intrinsic activity of the fusion proteins and not their synthesis rates, we measured the amount of labeled protein produced by a 1 -min pulse of $\left.{ }^{35} \mathrm{~S}\right]$ methionine. Proteins from labeled cells were immunopreciptated with anti-AP antibody and analyzed on SDS-polyacrylamide gels. All of the in-frame fusion strains produced approximately the same amount of labeled protein (data not shown). The strain with the out-offrame fusion (f118') produced a small amount of protein that comigrated with mature wild-type AP. This product probably arises from translational restart at an ATG in that frame, 6 codons before the insertion site. We assayed the AP activity of the cultures used for labeling and obtained results consistent with the values shown in Figure 2.

The fusions generated by transposition of TnphoA were located in both of the proposed periplasmic domains but in only the first cytoplasmic domain. From analysis of these fusions alone, it is formally possible to propose that the second cytoplasmic region indicated in Figure 2 is periplasmic, so that the protein would span the membrane only once. To test this possibility, we used oligonucleotide-directed mutagenesis to delete 84 nucleotides from the $\mathrm{f} 119$ fusion gene to produce fusion gene $\mathrm{f} 91$ (see Fig. 2). This deletion was made in a shortened version of the original $\mathrm{f} 119$ plasmid missing the $\mathrm{Kan}^{\mathrm{r}}$ and transposase functions of TnphoA (see Methods). To reduce potential problems associated with the overexpression of some of the fusion proteins, we used a strain (MJC98) with a $p c n B$ mutation, which reduces the copy number of ColE1-derived plasmids (Lopilato et al. 1986). Strain MJC98 transformed with the f91 plasmid produced $<1 \%$ of the activity produced by the corresponding f1 19 plasmid strain (15 versus 1900 units, respectively|. The low activity of the $\mathrm{f} 91$ fusion is consistent with the topology of SecE depicted in Figure 2, with the region between hydrophobic stretches 2 and 3 in the cytoplasm. Western blot analysis of the $\mathrm{f} 91$ fusion strain with anti-AP antibody revealed a protein of the expected size (data not shown).

We used the pJS51 :: TnphoA plasmids to confirm the hypothesis that the $13.6-\mathrm{kD}$ polypeptide was the $\sec E$ gene product. According to this hypothesis, plasmids with TnphoA insertions in the downstream ' $U$ ' gene should complement $\sec E$ mutations. Plasmids with insertions early in the $13.6-\mathrm{kD}$ ORF should fail to complement, whereas those with late insertions will complement only if they retain enough uninterrupted $\sec E$ sequence to function. We transformed strain PS8 (MC4100 secEcsE501 recA :: cat) with the pIS51 :: TnphoA plasmids at permissive temperature $\left(37^{\circ} \mathrm{C}\right)$ and tested for growth at the nonpermissive temperature $\left(23^{\circ} \mathrm{C}\right.$, see Table 2$)$. As expected, the plasmids with insertions in the ' $\mathrm{U}$ ' gene complemented the $\sec E$ allele, and insertions early in $\sec E$ (f15 and f24) failed to complement. Several of the other fusion plasmids, however, either failed to yield transformants or caused very slow growth of the transformants (Table 2). Even in the non-secE mutant strain PS169, these plasmids caused death or slow growth (Table 2). This phenomenon was strain dependent because transformants of $\mathrm{CCl} 18$ were affected much less strongly.

Plasmids containing two of the late insertions in $\sec E$, f1 $18^{\prime}$ and $f 119$, did complement the mutant phenotype. The $\mathrm{f} 118^{\prime}$ insertion is out-of-frame and results in a simple deletion of the last nine amino acids of SecE due to an in-frame stop codon at the fusion joint. The f119 fusion results in the replacement of the last seven amino acids of SecE by the TnphoA-encoded linker and AP sequences. Thus, the last amino acids of SecE are nonessential for complementation activity. The activity of the f1 19 insertion plasmid arises from either a bifunctional fusion protein or perhaps from a proteolyzed partial SecE. Surprisingly, the f124 fusion plasmid, which results in the replacement of only three amino acids from SecE, gives rise to transformants with a severe growth defect (Table 2).

Table 2. Transformation with TnphoA plasmids

\begin{tabular}{|c|c|c|c|}
\hline \multirow[b]{2}{*}{ Plasmid } & \multicolumn{2}{|c|}{$\begin{array}{l}\text { Transformation } \\
\text { of strain }\end{array}$} & \multirow{2}{*}{$\begin{array}{l}\text { Complementation of } \\
\frac{\sec E \operatorname{cs} E 501}{\text { in PS8 at } 23^{\circ} \mathrm{C}}\end{array}$} \\
\hline & PS169 & PS8 & \\
\hline fl5 & $\mathrm{L}$ & $L$ & - \\
\hline $\mathrm{f} 24$ & $\mathrm{~L}$ & $\mathbf{L}$ & - \\
\hline $\mathrm{f} 40$ & $S$ & nt & nt \\
\hline $\mathrm{f} 50$ & $S$ & $\mathrm{nt}$ & nt \\
\hline f1 12 & $\mathrm{~T}$ & nt & nt \\
\hline f115 & nt & nt & nt \\
\hline fll18 & $\mathbf{L}$ & L & + \\
\hline fl 19 & L & $\mathrm{L}$ & + \\
\hline $\mathrm{f} 124$ & $\mathrm{nt}$ & $\mathrm{nt}$ & nt \\
\hline Uf3 & $\mathrm{L}$ & $\mathrm{L}$ & + \\
\hline Uf6 & $\mathrm{L}$ & $\mathrm{L}$ & + \\
\hline pIS5l & $\mathbf{L}$ & $\mathrm{L}$ & + \\
\hline Bluescript & L & $\mathrm{L}$ & - \\
\hline pBRU & $\mathrm{L}$ & $\mathrm{L}$ & + \\
\hline pBR322 & $\mathrm{L}$ & $\mathrm{L}$ & - \\
\hline
\end{tabular}

Strains PS169 and PS8 were transformed to $\mathrm{Amp}^{\mathrm{r}}$ or $\mathrm{Kan}^{\mathrm{r}}$ at $37^{\circ} \mathrm{C}$ with the pJS51 :: TnphoA fusion plasmids or control plasmids indicated. Colony size was scored as large (L), small (S), or tiny (T). Plasmids that yielded no transformants or barely discernible transformants are scored $n t$. The transformants of PS8 were streaked at $23^{\circ} \mathrm{C}$ and scored for growth $(+)$ or no growth $(-1$. 


\section{Cellular location of the f119 fusion protein}

The ability of the f119 fusion gene to complement the secE mutant phenotype suggests that the f1 19 protein might be assembled into the cellular location where SecE normally functions. Thus, in the absence of a specific probe for SecE, we used the fl 119 protein as a marker for the normal location of SecE. We fractionated cells expressing the f 119 protein using two methods. The first method used was precipitation of membranes by treatment with base (Russel and Model 1982). Most cytoplasmic and periplasmic proteins remain in the supernatant after treatment of cells with $0.1 \mathrm{M} \mathrm{NaOH}$, whereas inner and outer membrane proteins appear in the pellet. The full-length $\mathrm{fl} 19$ protein cofractionated with membranes by this test, whereas most of the mature AP from a control strain appeared in the cytoplasm/periplasm fraction (data not shown).

To confirm the apparent membrane localization of fl19 fusion and to determine which membrane contained the protein, we fractionated membranes by sucrose gradient centrifugation (Osborn et al. 1972; Osborn and Munson 1974). To reduce problems associated with overexpression of the fusion protein, we first constructed strains in which the fusion gene was carried in single copy in a lysogenic state by a derivative of phage $\lambda$ YU101. We generated spheroplasts of these strains with lysozyme/EDTA and lysed them by osmotic shock. After a low-speed spin to remove unlysed spheroplasts, we isolated the membranes with a high-speed spin, leaving cytoplasmic and periplasmic proteins in the supernatant. We fractionated the resulting membranes by isopycnic centrifugation on a sucrose gradient.

The analysis of a representative sucrose gradient is shown in Figure 3. We observed three visible bands of membrane in the gradient. As detected by AP activity, the fll 19 fusion protein cofractionated almost exactly with the inner membrane marker NADH oxidase into the two lightest bands (1.15 and $1.20 \mathrm{~g} / \mathrm{ml}$, respectively).
As detected by a Western blot, the outer membrane protein OmpA was present mostly in the two heaviest bands $(1.20$ and $1.22 \mathrm{~g} / \mathrm{ml})$. Previous work has shown that the heavy and light bands contain outer and inner membrane, respectively, whereas the intermediate band contains substantial amounts of both (Osborn and Munson 1974). Thus, the fl 19 fusion protein appears to be associated with the inner membrane.

When we performed the gradient analysis on a strain that expressed both intact AP and the f1 19 fusion, intact AP was present mostly in the supernatant when the membranes were pelleted originally, indicating a periplasmic location. When the strain used contained only the $\mathrm{f} 119$ gene, only $6 \%$ of the AP activity was in the supernatant, consistent with the low level of proteolysis of the f119 fusion joint observed on Western blots. We conclude that the SecE portion of the fusion protein causes it to be localized to the inner membrane. The proteolysis of the fusion protein leaves open the question of whether its intact form has SecE activity, because of uncertainty about the amount of protein required for complementation of the secEcsE501 mutation.

\section{Isolation of additional secE alleles}

Only one allele of $\sec E$ that exhibits a secretion defect and conditional lethality has been reported previously (Riggs et al. 1988). To obtain more evidence for the involvement of the $\sec E$ gene in secretion, we isolated additional alleles using localized mutagenesis (Hong and Ames 1971). The region near secE was mutagenized by transduction of the linked $\arg E:: \operatorname{Tn} 10$ marker from a mutator strain (MUTl $\arg E:: \operatorname{Tn} 10$ ) into strain PR478. We selected transductants on TYE XG tPEG tetracycline citrate plates (see Methods) and screened for the presence of blue colonies that indicated overexpression of the $\sec A-l a c Z$ fusion. Several of these colonies exhibited cold-sensitive lethality at $23^{\circ} \mathrm{C}$ when tested on plates of the same type.
Figure 3. Localization of the $\mathrm{f} 119$ fusion protein. Membranes isolated from a strain carrying $\lambda$ PS3 were resuspended in $25 \%$ sucrose, $5 \mathrm{~mm}$ EDTA, and run on a $55-30 \%$ sucrose gradient at 35,000 rpm for $16 \mathrm{hr}$. The even fractions were analyzed for AP activity, NADH oxidase activity (inner membrane), and density. AP units were defined as $\mathrm{A}_{420} \times 1000 /$ (volume $\times$ time) in a $1-\mathrm{ml}$ reaction. NADH oxidase units are arbitrary. The region containing the majority of the outer membrane protein OmpA, as determined by western blotting, is indicated. ( $\square$ ) AP activity; $(\checkmark) \mathrm{NADH}$ oxidase; (ㅇ) density $=$ grams per milliliter.

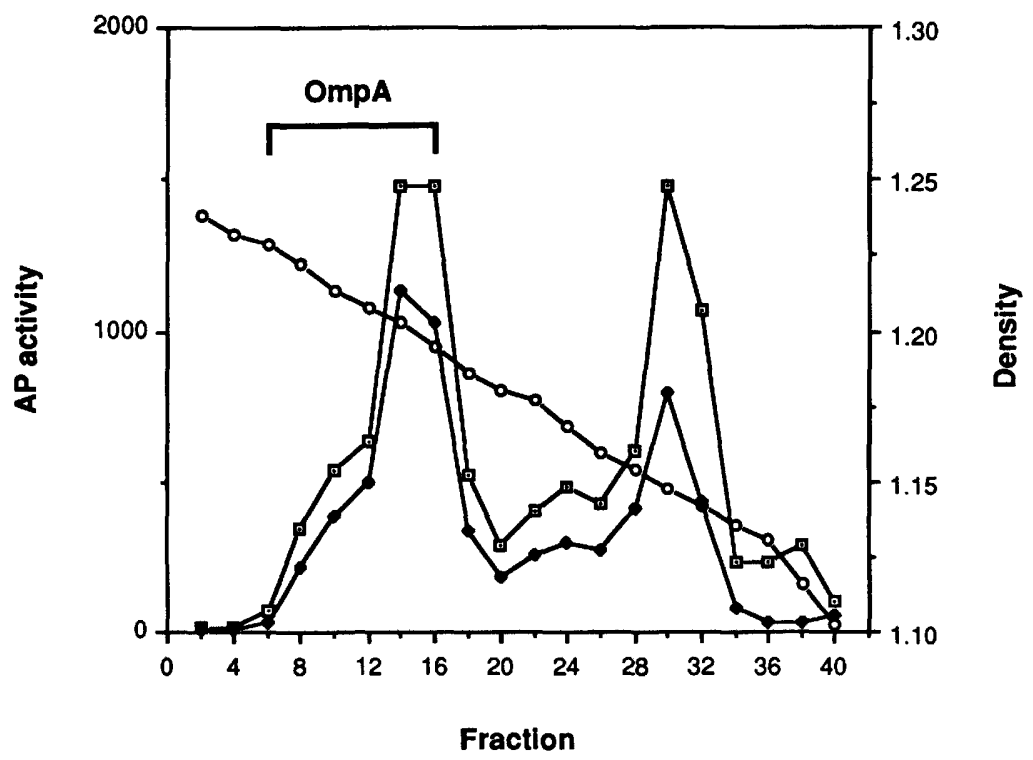


We tested prospective mutants in several ways to establish that they contained alleles of $\sec E$. We tested for linkage between the $\arg E:: \operatorname{Tn} 10$ marker and the mutation by P1 transduction into PR478. Four independent alleles showed linkage to the $\arg E:: \operatorname{Tn} 10$. In all of these crosses, cold sensitivity was linked to the $\sec A-1 a c Z$ overexpression phenotype. To demonstrate conclusively that these mutations were alleles of $\sec E$, we performed complementation tests with the $\sec E$ plasmids described above. Both phenotypes of all four mutants were complemented by pBRU and pIS51 but not by the vectors pBR322 or Bluescript. The f24 early insertion in the pJS51 secE plasmid also failed to complement. We conclude that these four mutations are alleles of the $\sec E$ gene and have designated them secEcs11, secEcs12, secECs13, and secEcs14.

The cold-sensitive phenotype caused by all of these mutations, however, was dependent on the medium. On the TYE XG TPEG tetracycline citrate plates originally used for the transductions, all of the mutants were cold sensitive. When tetracycline was not present, none of the mutants were cold sensitive. This phenomenon appeared to be due to the expression of the tetracycline resistance gene from $\operatorname{Tn} 10$ and not an effect of active tetracycline. This conclusion is based on the observation that autoclaved chlortetracycline in the medium, which does not kill cells but does induce the tetracycline resistance gene (Bochner et al. 1980), exhibited the same effect as active tetracycline. Also, strains containing the new alleles, but without the Tn10, were not cold sensitive on any medium tested. We do not know the origin of the interaction between the tetracycline resistance protein and $\sec E$. The tetracycline protein, however, is an inner membrane protein that has pleiotropic effects on membrane permeability (Griffith et al. 1988).

We tested the four new $\sec E$ alleles for a possible secretion defect. We grew strains PS137, PS138, PS139, and PS140 in M63 maltose medium at $37^{\circ} \mathrm{C}$ and then shifted them to $23^{\circ} \mathrm{C}$ for $3 \mathrm{hr}$. We labeled cellular proteins with a 1-min pulse of $\left[{ }^{35} \mathrm{~S}\right]$ methionine, both before and after the shift and analyzed immunoprecipitated MBP on SDS-PAGE gels. After the shift, all of the mutants exhibited a significant increase in the ratio of precursor to mature MBP, compared with PS141, the wildtype control (data not shown). The secretion defect was present even in mutants grown under permissive conditions in the absence of tetracycline. We conclude that a secretion defect is a general property of $\sec E$ mutants isolated by the $\sec A-l a c Z$ method.

\section{Discussion}

The genetic screening procedure we have used relies on the finding that mutations in $s e c$ genes cause derepression of a secA-lacZ fusion (Riggs et al. 1988). This derepression occurs in strains where there are only partial defects in protein export, either at the permissive temperature with conditional lethal mutants or with mutants that only partly block export at all temperatures. At nonpermissive temperatures the derepression is even greater. Because the $\sec A$ gene is an essential gene (Oliver and Beckwith 1982) and conditional lethals have been found in $\sec D, \sec E$, and $p r l A / \sec Y$ (Shiba et al. 1984; Gardel et al. 1987; Riggs et al. 1988), it appears probable that the genes of this pathway are all essential.

The genetic screening procedure used here yields mutants in several of the sec genes. The only sec gene that was not detected was $\sec B$. It has been shown that $\sec B$ mutants do not derepress the $\sec A$ gene (Rollo and Oliver 1988). In addition, $\sec B$ mutants are the only class of sec mutants that do not show wide pleiotropy (Kumamoto and Beckwith 1985). In contrast to the other mutants, sec $B$ mutants only affect the export of a subset of cell-envelope proteins. It has been suggested that $\sec B$ may play a role in affecting the intracellular conformation of this subset (Collier et al. 1988).

Using this screening procedure, mutations that lie in the $\sec A, \sec D$, and $\operatorname{pr} I A / \sec Y$ genes have been detected repeatedly. Only one mutation was found that did not map to one of these three genes and, at the same time, caused a protein export defect. This was the cold-sensitive mutation in the $\sec E$ gene (Riggs et al. 1988). The frequency of appearance of this mutation in comparison to those in the other genes may be related to the small size of the secE gene. The products or presumed products of the $\sec A, \sec E$, and $\mathrm{prl} A / \sec Y$ have molecular weights of $95,000,13,600$, and 68,000 , respectively. The molecular weight of $\sec D$ has not been established. Thus, secE presents a considerably smaller target for mutagenesis than the other characterized genes. The classification of it as a sec gene has been strengthened in this paper by the isolation of four additional alleles, all of which exhibit secretion defects. In addition, Stader et al. (1989) describe a new class of extragenic suppressor of signal sequence mutations, called $p r l G$, which are linked tightly to and probably map in the $\sec E$ gene. The observation of both secretion defects and signal-sequence suppression as phenotypes of the same gene strongly argues that SecE plays an important role in E. coli protein export.

We now consider whether all possible $\sec$ genes have been identified. The fact that this very general selection and screening procedure among 60 mutants yielded only mutations in the known $\sec$ genes plus $\sec E$ raises the possibility that there may be no more genes to be found. The identified sec genes affect both soluble and membrane-bound components of the export machinery (Oliver and Beckwith 1982; Akiyama and Ito 1985; Collier et al. 1988; Kumamoto et al. 1989|. Factors that recognize signal sequence-containing proteins, as well as membrane receptors and even a pore within the membrane, may be included among these gene products. That mutations in different steps of the export process, as well as other factors that block secretion, cause a derepression of the secA gene strengthens the suggestion that this genetic screening approach is quite a general one. If this assumption is correct, then we may have missed additional sec genes only for one of the following reasons: (1) Another $\mathrm{sec}$ gene exists in which it is difficult to detect mutations due to small size or other 
reasons; (2) another gene(s) like $\sec B$ exists that does not induce $s e c A$ derepression because it affects only a subset of proteins; (3) mutations in genes encoding membrane proteins involved in the very late steps in protein translocation do not cause $\sec A$ derepression. Only reconstitution of an in vitro system from purified components will demonstrate conclusively that no other gene products are required for proteins to traverse the bacterial membrane.

The limited number of genes identified by this approach and the failure to find any that are identical to genes in other known pathways indicate that this procedure is not detecting mutants generally involved in membrane biogenesis. For instance, one might have imagined that mutations in genes in certain fatty acid biosynthetic genes might have affected the membrane so as to interfere with secretion.

\section{SecE is an integral membrane protein}

In this paper we identify the location of the $S e c E$ gene in a region sequenced by Downing and co-workers, adjacent to a gene, ' $U$ ', that is involved in transcription (W. Downing, S. Sullivan, M. Gottesman, and P. Dennis, in prep.). An inspection of the $\sec E$ sequence suggests that the gene product is an integral cytoplasmic membrane protein. This suggestion is strengthened by the isolation of alkaline phosphatase (AP) fusions to secE. The position of fusion joints which correlate with high levels of AP activity also leads to a tentative model for the arrangement of this protein in the membrane (Fig. 2). As shown previously, high levels of AP activity in such fusions indicate the location of the periplasmic domains of membrane proteins (Manoil and Beckwith 1986).

One of the late in-frame fusion genes, f1 19, appears to retain sufficient $\sec E$ activity so that the plasmid can complement the secEcsE501 allele. This result indicates that the SecE portion of the protein may be assuming its normal conformation in the membrane, thus supporting the validity of using AP fusions to analyze membrane protein topology. Alternatively, it is possible that the complementation is due to low-level proteolysis of the fusion protein. The intact $\mathrm{f} 119$ protein was localized to the $E$. coli inner membrane because of the presence of the SecE sequences, implying that SecE normally functions in that membrane.

We used the FASTA program (Pearson and Lipman 1988) to search for any genes that might have sequence similarity to $\sec E$. One of the genes identified in this search was the $\sec Y$ gene. The area of closest similarity is shown in Figure 4 (24\% identity over a 72 -amino-acid stretch with no gaps). This region consists of membrane-spanning stretches 2 and 3 of $\operatorname{SecE}$, along with the hydrophilic region between them. It aligns with a portion of SecY containing membrane-spanning stretches 2 and 3 (Akiyama and Ito 1987). The proposed topology of SecE in this area is identical to that proposed for SecY by Akiyama and Ito (1987). The significance of the similarity was tested using the IALIGN program (National Biomedical Research Foundation) over the 72-amino-

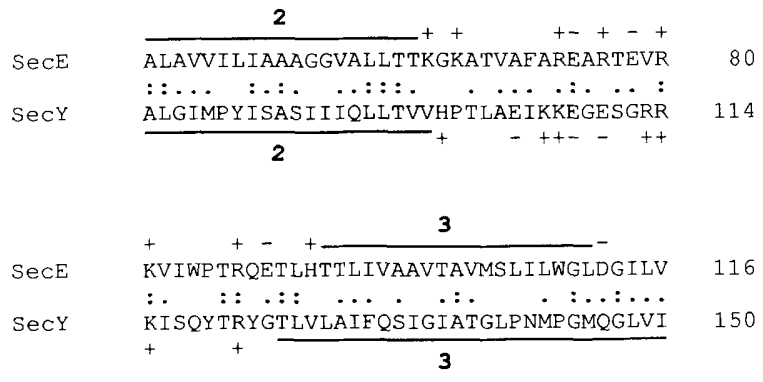

Figure 4. Similarity of SecE to SecY. A region of sequence similarity between SecE and SecY is shown, including membrane spanning segments 2 and 3 of each. (:) Amino acid identity; (.) conservative changes. Of 72 amino acids, 17 are identical in the region $(24 \%)$, with no gaps. Charged amino acids are designated above and below the lines.

acid region of similarity. The alignment score was 5.7 , which is less than the recommended score of 6.0 , so this similarity may be explained simply by the fact that both are membrane proteins and are expected to have more similarities than either would to soluble proteins.

Whether or not these similarities have any significance, it seems possible that the SecY and SecE products may interact in the membrane. One possibility is that together they form a pore through which exported proteins pass. At any rate, the small size of the $\sec E$ gene should allow a detailed mutational study and a correlation of mutational sites with particular phenotypes.

\section{Methods}

\section{Materials}

tPEG, 5-bromo-4-chloro-3-indolyl- $\beta$-D-galactopyranoside (XG) and 5-bromo-4-chloro-3-indolyl phosphate (XP) were purchased from Bachem. Restriction enzymes and T4 DNA ligase were purchased from New England BioLabs.

\section{Media and bacterial strains}

Media for bacterial and phage growth have been described (Maniatis et al. 1982; Riggs et al. 1988). The E. coli strains used are shown in Table 1.

\section{Phage strains}

$\lambda$ PR9 is a $\lambda$ imm 21 phage carrying the $\sec A^{+}$and $e n v A^{+}$genes (Riggs et al. 1988). $\lambda$ drifd 18 is a defective $\lambda$ cIts857 S7 specialized transducing phage carrying a portion of the $E$. coli chromosome from rpoC to $r \mathrm{rnB}$ (Kirschbaum and Konrad 1973). $\lambda$ YU101 (kindly provided by S. Sullivan and M. Gottesman) is a $\lambda$ cIts857 int $^{-}$phage carrying a portion of the $E$. coli chromosome from the EcoRI site in rplK to the SmaI site in $t u f B$ (see Fig. 1; An and Friesen 1980) The SmaI site has been converted to an $E c o R I$ site with a linker. $\lambda$ PS3 is a derivative of $\lambda$ YU101 carrying the $\sec E::$ phoA $\mathrm{fl} 19$ fusion gene. To construct $\lambda$ PS 3 , the transposase and $\operatorname{Kan}^{\mathrm{r}}$ functions were deleted from the original plasmid by cleavage with $X h o I$ and reclosure with ligase. This plasmid was introduced into strain MJC98. A lysate of $\lambda$ YU101 grown on this strain was examined for the presence of phage that had acquired the fusion gene by recombination by looking 
for phage that made blue plaques on strain CC118 on XP medium. The presence of the fusion gene was confirmed by restriction mapping of phage DNA.

\section{Genetic techniques}

Phage P1 transductions and E. coli conjugation experiments were carried out as described by Miller (1972). Thermostable lysogens of $\lambda$ cIts857 phage were made as follows: PR500 was grown to $2 \times 10^{8}$ cells $/ \mathrm{ml}$ in Luria broth $(\mathrm{LB})+0.2 \%$ maltose, harvested by low-speed centrifugation, and resuspended in 10 $\mathrm{mM} \mathrm{MgSO}{ }_{4}$. For $\lambda \mathrm{drif}{ }^{\mathrm{d}} 18$, the cells were infected with $\lambda c \mathrm{I}^{+}$at a m.o.i. of 10 per cell and with $\lambda$ drif 18 at a m.o.i. of 0.1 and plated on $\mathrm{LB}+$ rifampicin at $37^{\circ} \mathrm{C}$. For $\lambda$ YU101, the cells were infected with $\lambda \mathrm{cI}^{+}$at a m.o.i. of 10 per cell and with $\lambda$ YU101 at a m.o.i. of 1 , and plated on $\mathrm{LB}$ at $37^{\circ} \mathrm{C}$. Cells were screened for immunity and the release of both phage after UV induction.

\section{Isolation of mutants}

Mutants that overexpressed the $\sec A-l a c Z$ fusion were isolated as described previously (Riggs et al. 1988).

\section{Plasmid constructions}

The plasmid pBRU (kindly provided by S. Sullivan and M. Gottesman/ contains the 2.2-kb EcoRI fragment carried by $\lambda$ YU101 inserted into pBR322. The plasmid pIS51 was constructed by inserting a $0.8-\mathrm{kb} K p n I-E a g I$ fragment from $\mathrm{pBRU}$ into the vector Bluescript KS $\mathrm{Ml3}^{+}$(Stratagene Cloning Systems, Inc.). This fragment contains the end of the tuf $B$ gene, the secE gene, and the beginning of the ' $U$ ' gene (see Fig. 1). Insertions of transposon TnphoA (Manoil and Beckwith 1985) into pJS51 were isolated using $\lambda$ TnphoA (Gutierrez et al. 1987) by a procedure similar to one described previously (Boyd et al. 1987a). Strain CC118 carrying the plasmid was grown to early stationary phase and infected with $\lambda$ TnphoA at a m.o.i. of 1 . After absorption of the phage, the culture was diluted $1: 10$ in LB medium, divided into 50 separate cultures, and grown overnight at $30^{\circ} \mathrm{C}$. Then $0.2 \mathrm{ml}$ of each culture was plated on TYE agar containing $100 \mu \mathrm{g} / \mathrm{ml}$ ampicillin, $300 \mu \mathrm{g} / \mathrm{ml}$ kanamycin, and $40 \mu \mathrm{g} / \mathrm{ml} \mathrm{XP}$. Pools of plasmids were prepared from each plate and reintroduced into $\mathrm{CCl18}$. Plasmids containing insertions in the secE-' $\mathrm{U}^{\prime}$ region were identified as those that conferred ampicillin and kanamycin resistance and exhibited some detectable level of AP activity (blue on XP medium). The TnphoA insertion sites of 95 plasmids were analyzed by restriction mapping and 11 plasmids were selected for detailed study.

Oligonucleotide-directed mutagenesis was performed essentially as described in the Bluescript instruction manual (Stratagene).

\section{Sequencing}

DNA sequence analysis was performed using Sequenase (U.S. Biochemicall by the procedure described in the manual. Double-stranded DNA was prepared by the method of Zagursky et al. (1985), except that the RNase step was performed at $\mathrm{pH}$ 7.5 followed by two extractions with phenol and two extractions with $\mathrm{CHCl}_{3}$.

\section{Assays}

AP activity was measured by determining the rate of $p$-nitrophenyl phosphate hydrolysis in permeablized cells normalized to the $A_{600}$ of the cell suspension (Michaelis et al. 1983). NADH oxidase activity was determined as described by Osborn et al. (1972).

\section{Cell fractionations and immunoprecipitations}

Cellular proteins associated with membranes were identified by the $\mathrm{NaOH}$ precipitation method of Russel and Model (1982). Inner and outer membranes were separated by sucrose gradient centrifugation, as described by Osborn and Munson (1974), except that the membranes were only pelleted once at $50,000 \mathrm{rpm}$ for 90 min in a Beckman type 65 rotor. Procedures for labeling cells, immunoprecipitations, and gel electrophoresis have been described (Ito et al. 1981; Strauch et al. 1986). Western blots were stained using the Protoblot AP system (Promega), essentially as described in the manual.

\section{Acknowledgments}

We thank S. Sullivan, M. Gottesman, W. Downing, and P. Dennis for communicating results prior to publication and for providing plasmid and phage strains. We thank P.C. Tai for anti-OmpA antibody and C. Gardel for anti-AP antibody. This work was supported by grant DMB-8216464 from the National Science Foundation. P.J.S. was supported by a Damon RunyonWalter Winchell Cancer Research Fund Fellowship (DRG-985). P.D.R. was supported by a National Institutes of Health postdoctoral fellowship. A.J. was supported by a fellowship from the American Cancer Society, Massachusetts Division, and from the Philippe Foundation. M.J.F. was supported by a National Institutes of Health predoctoral fellowship.

\section{Note added in proof}

Strains that carried a $p c n B$ mutation did not exhibit the severe growth defect associated with some of the pIS51 :: TnphoA plasmids in non-pcnB strains (Table 2). In such strains, the f1 12, f1 15, f118', f1 19, and f124 plasmids complemented the cold sensitivity caused by the secEcsE501 mutation, whereas the $\mathrm{f} 15, \mathrm{f} 24, \mathrm{f} 40$, and $\mathrm{f} 50$ plasmids failed to complement.

\section{References}

Akiyama, Y. and K. Ito. 1985. The SecY membrane component of the bacterial protein export machinery: Analysis by new electrophoretic methods for integral membrane proteins. EMBO J. 4: 3351-3356.

. 1987. Topology analysis of the SecY protein, an integral membrane protein involved in protein export in Escherichia coli. EMBO J. 6: 3465-3470.

An, G. and J.D. Friesen. 1980. Characterization of promotercloning plasmids: Analysis of operon structure in the rif region of Escherichia coli and isolation of an enhanced internal promoter mutant. J. Bacteriol. 144: 904-916.

Bacallo, R., E. Crooke, K. Shiba, W. Wickner, and K. Ito. 1986. The secY protein can act post-translationally to promote bacterial protein export. J. Biol. Chem. 261: 12907-12910.

Bankaitis, V.A. and P.J. Bassford, Jr. 1985. Proper interaction between at least two components is required for efficient export of proteins to the Escherichia coli cell envelope. $J$. Bacteriol. 161: 169-178.

Bochner, B.R., H.-C. Huang, G.L. Schieven, and B.N. Ames. 1980. Positive selection for loss of tetracycline resistance. I. Bacteriol. 143: 926-933. 
Boyd, D., C. Manoil, and J. Beckwith. 1987a. Determinants of membrane protein topology. Proc. Natl. Acad. Sci. 84: 8525-8529.

Boyd, D., C.-D. Guan, S. Willard, W. Wright, K. Strauch, and J. Beckwith. 1987b. Enzymatic activity of alkaline phosphatase precursor depends on its cellular location. Phosphate metabolism and cellular regulation in microorganisms fed. A. Torriani-Gorini, F.G. Rothman, S. Silver, A. Wright, and E. Yagil), pp. 89-93. American Society for Microbiology, Washington, D.C.

Cabelli, R.J., L. Chen, P.C. Tai, and D.B. Oliver. 1988. SecA protein is required for secretory protein translocation into $E$. coli membrane vesicles. Cell 55: 683-692.

Collier, D.N., V.A Bankaitis, J.B. Weiss, and P.J. Bassford, Jr. 1988. The antifolding activity of $\mathrm{SecB}$ promotes the export of the E. coli maltose-binding protein. Cell 53: 273- 283.

Emr, S.D., S. Hanley-Way, and T.J. Silhavy. 1981. Suppressor mutations that restore export of a protein with a defective signal sequence. Cell 23: $79-88$.

Fandl, J.P. and P.C. Tai. 1987. Biochemical evidence for the secY24 defect in Escherichia coli protein translocation and its suppression by soluble cytoplasmic factors. Proc. Natl. Acad. Sci. 84: 7448-7452.

Fiil, N.P., D. Bendiak, J. Collins, and J.D. Priesen. 1979. Expression of $E$. coli ribosomal protein and RNA polymerase genes cloned on plasmids. Mol. Gen. Genet. 173: 39-50.

Gardel, C., S. Benson, J. Hunt, S. Michaelis, and J. Beckwith. 1987. secD, a new gene involved in protein export in Escherichia coli. J. Bacteriol. 169: 1286-1290.

Griffith, J.K., T. Kogoma, D.L. Corvo, W.L. Anderson, and A.L. Kazim. 1988. An n-terminal domain of the tetracycline resistance protein increases susceptibility to aminoglycosides and complements potassium uptake defects in Escherichia coli. J. Bacteriol. 170: 598-604.

Gutierrez, C., J. Barondess, C. Manoil, and J. Beckwith. 1987. The use of transposon TnphoA to detect genes for cell envelope proteins subject to a common regulatory stimulus. $I$. Mol. Biol. 195: 289-297.

Hong, J.-S. and B.N. Ames. 1971. Localization mutagenesis of any specific small region of the bacterial chromosome. Proc. Natl. Acad. Sci. 68: 3158-3162.

Ito, K., P.J. Bassford, Jr., and J. Beckwith. 1981. Protein localization in E. coli: Is there a common step in the secretion of periplasmic and outer-membrane proteins? Cell 24: 707717.

Kirschbaum, J.B. and E.B. Konrad. 1973. Isolation of a specialized $\lambda$ transducing bacteriophage carrying the beta subunit gene for Escherichia coli ribonucleic acid polymerase. I. Bacteriol. 116: 517-526.

Kumamoto, C. and J. Beckwith. 1983. Mutations in a new gene, $\sec B$, cause defective protein localization in Escherichia coli. J. Bacteriol. 154: 254-260.

- 1985 . Evidence for specificity at an early step in protein export in Escherichia coli. J. Bacteriol. 163: 267-274.

Kumamoto, C.A., L. Chen, J. Fandl, and P.C. Tai. 1989. Purification of the Escherichia coli $\sec B$ gene product and demonstration of its activity in an in vitro protein translocation system. J. Biol. Chem. 264: 2242-2249.

Kyte, J. and R.F. Doolittle. 1982. A simple method for displaying the hydropathic character of a protein. J. Mol. Biol. 157: $105-132$.

Lee, C.A. and J. Beckwith. 1986. Suppression of growth and protein secretion defects in Escherichia coli secA mutants by decreasing protein synthesis. J. Bacteriol. 166: 878-883.

Lopilato, J., S. Bortner, and J. Beckwith. 1986. Mutations in a new chromosomal gene of Escherichia coli K-12, pcnB, re- duce plasmid copy number of pBR322 and its derivatives. Mol. Gen. Genet. 205: 285-290.

Maniatis, T., E.F. Fritsch, and J. Sambrook. 1982. Molecular cloning: A laboratory manual. Cold Spring Harbor Laboratory, Cold Spring Harbor, New York.

Manoil, C. and J. Beckwith. 1985. TnphoA: A transposon probe for protein export signals. Proc. Natl. Acad. Sci. 82: 81298133.

- 1986. A genetic approach to analyzing membrane protein topology. Science 233: 1403-1408.

Michaelis, S., H. Inouye, D. Oliver, and J. Beckwith. 1983. Mutations that alter the signal sequence of alkaline phosphatase in Escherichia coli K-12. J. Bacteriol. 154: 366-374.

Miller, J.H. 1972. Experiments in molecular genetics. Cold Spring Harbor Laboratory, Cold Spring Harbor, New York.

Oliver, D.B. and J. Beckwith. 1981. E. coli mutant pleiotropically defective in the export of secreted proteins. Cell 25: $2765-2772$.

- 1982. Regulation of a membrane component required for protein secretion in Escherichia coli. Cell 30: 311-319.

Osborn, M.J. and R. Munson. 1974. Separation of the inner (cytoplasmic) and outer membranes of gram-negative bacteria. Methods Enzymol. 31: 642-653.

Osborn, M.J., J.E. Gander, E. Parisi, and J. Carson. 1972. Mechanism of assembly of the outer membrane of Salmonella typhimurium: isolation and characterization of cytoplasmic and outer membrane. J. Biol. Chem. 247: 3962-3972.

Pearson, W.R. and D.J. Lipman. 1988. Improved tools for biological sequence comparison. Proc. Nat1. Acad. Sci. 85: 24442448.

Riggs, P.D., A.I. Derman, and J. Beckwith. 1988. A mutation affecting the regulation of a $\sec A-l a c Z$ fusion defines a new sec gene. Genetics 118: 571-579.

Rollo, E.R. and D.B. Oliver. 1988. Regulation of the Escherichia coli $\sec A$ gene by protein secretion defects: Analysis of $\sec A$, $\sec B, \sec D$, and $\sec Y$ mutants. I. Bacteriol. 170: 32813282 .

Russel, M. and P. Model. 1982. Filamentous phage pre-coat is an integral membrane protein: Analysis by a new method of membrane preparation. Cell 28: 177-184.

Shiba, K., K. Ito, T. Yura, and D.P. Cerretti. 1984. A defined mutation in the protein export gene within the spc ribosomal protein operon of Escherichia coli: Isolation and characterization of a new temperature-sensitive $\sec Y$ mutant. EMBO. J. 3: 631-636.

Stader, J.A., L.J. Gansheroff, and T.J. Silhavy. 1989. New suppressors of signal sequence mutations, prlG, are tightly linked to the secE gene of Escherichia coli. Genes Dev. 3:.

Strauch, K.L., C.A. Kumamoto, and J. Beckwith. 1986. Does $\sec A$ mediate coupling between secretion and translation in Escherichia coli? J. Bacteriol. 166: 505-512.

Yamamoto, M. and M. Nomura. 1979. Organization of genes for transcription and translation in the rif region of the Esche richia coli chromosome. I. Bacteriol. 137: 584- 594.

Zagursky, R.J., K. Baumeister, N. Lomax, and M.L. Berman. 1985. Rapid and easy sequencing of large linear doublestranded DNA and supercoiled plasmid DNA. Gene Anal. Technol. 2: 89-94. 


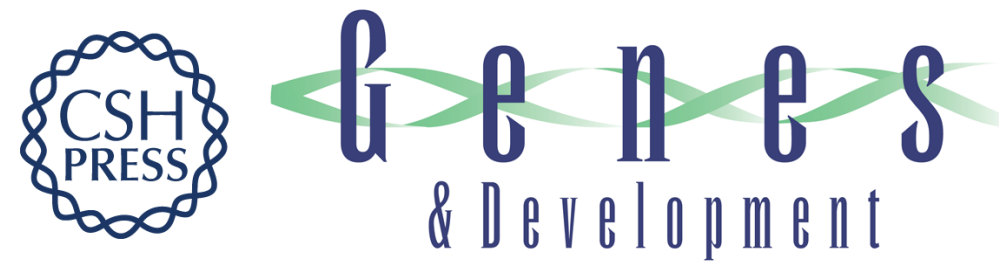

\section{The secE gene encodes an integral membrane protein required for protein export in Escherichia coli.}

P J Schatz, P D Riggs, A Jacq, et al.

Genes Dev. 1989, 3:

Access the most recent version at doi:10.1101/gad.3.7.1035

References This article cites 39 articles, 22 of which can be accessed free at: http://genesdev.cshlp.org/content/3/7/1035.full.html\#ref-list-1

License

Email Alerting

Service

Receive free email alerts when new articles cite this article - sign up in the box at the top right corner of the article or click here.

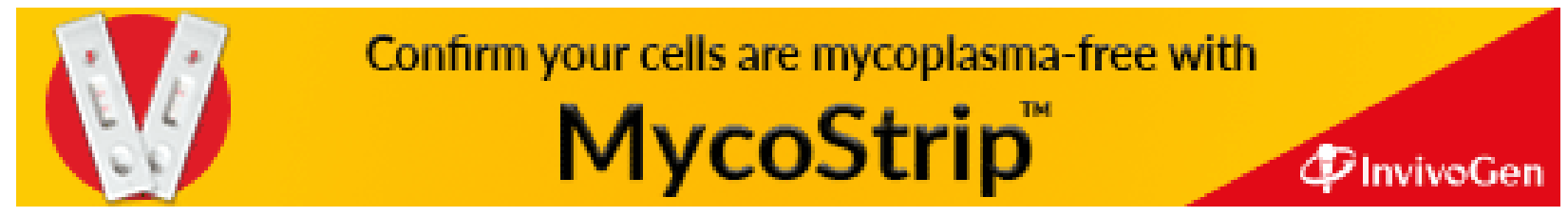

